Analytical Letters, 2007, 40(7), 1412-1442.

\title{
"Labeless Immunosensor Assay for Fluoroquinolone Antibiotics based upon an AC Impedance Protocol",
}

Goulielmos-Zois Garifallou ${ }^{1}$, Georgios Tsekenis ${ }^{1}$, Frank Davis ${ }^{1}$, Paul A. Millner ${ }^{2}$ Daniel G. Pinacho ${ }^{3}$, Francisco Sanchez-Baeza ${ }^{3}$, M.-Pilar Marco ${ }^{3}$, Tim D. Gibson ${ }^{4}$ and Séamus P. J. Higson ${ }^{1}$.

${ }^{1}$ Cranfield Health, Cranfield University, Silsoe, Beds, MK45 4DT, UK.

${ }^{2}$ School of Biochemistry and Molecular Biology, University of Leeds, Leeds, LS2 9JT, UK.

${ }^{3}$ Applied Molecular Receptors Group (AMRg). Department of Biological Organic Chemistry. IIQAB-CSIC. Jorge Girona, 18-26, 08034-Barcelona, Spain ${ }_{4} \mathrm{~T}$ and D Technology, Wakefield, W. Yorks, WF3 4AA, UK.

.Corresponding author. Fax (+44) 01525 863433, email s.p.j .higson@ cranfield.ac.uk 


\begin{abstract}
.
This paper describes the construction of a labeless immunosensor for the antibiotic ciprofloxacin and its interrogation using an AC impedance protocol. Commercial screen-printed carbon electrodes were used as the basis for the sensor. Polyaniline was electrodeposited onto the sensors and then utilised to immobilise a biotinylated antibody for ciprofloxacin using classical avidin-biotin interactions.

Electrodes containing the antibodies were exposed to solutions of antigen and interrogated using an AC impedance protocol. The faradaic component of the impedance of the electrodes was found to increase with increasing concentration of antigen. Control samples containing a non-specific IgG antibody were also studied and calibration curves obtained by subtraction of the responses for specific and non-specific antibody based sensors, thereby eliminating the effects of non-specific adsorption of antigen.
\end{abstract}

Keywords: fluoroquinolone, ciprofloxacin, AC impedance, immunosensor, polyaniline. 


\section{INTRODUCTION}

The principle of immunoas says was established in 1959 by Yalow and Berson (Yalow \& Berson, 1959). Their work developed the widely used radioimmunoassay to examine the properties of insulin-binding antibodies in human serum, using samples obtained from subjects that had been treated with insulin.

Following the newly developed immunoassay technique, the concept of a biosensor was pioneered by Clark and Lyons in 1962 (Clark \& Lyons, 1962). The original methodology was to immobilise enzymes on the surface of electrochemical sensors-assuming that this would enhance the ability of a sensor to detect specific analytes. This idea has remained virtually unchanged since this original design, however, technological advances have allowed for the expansion of this field of science.

The incorporation of antibodies into conducting polymer films was first reported in 1991 (John et al 1991). Anti-human serum albumin (anti-HSA) was incorporated into a polypyrrole film, which was galvanostatically polymerised onto a platinum wire substrate. When grown in the absence of a counterion, a poor polymeric film, both in appearance and electrochemical properties was formed, suggesting that the presence of a counterion was necessary for the polymerisation process to be successful. Amino acid analysis of the polymer using a leucine marker showed that approximately $0.1 \% \mathrm{w} / \mathrm{v}$ $(0.2 \mathrm{Pg})$ of the antibody was incorporated into

the matrix. When the pyrrole anti-HSA electrode was exposed to $50 \mathrm{Pg} \mathrm{ml}^{-1} \mathrm{HSA}$ for ten minutes, a new reduction peak was observed at a potential of approximately $+600 \mathrm{mV}$ vs. $\mathrm{Ag} / \mathrm{AgCl}$. This peak increased in magnitude after a further thirty minutes in the same solution and it was suggested this could be due to an antibody/antigen interaction with the polymer. Further work by the same group gave rise to reports of a

reversible real-time immunosensor (John et al 1991). Other early work utilised a pulsed 
amperometric detection technique for other analytes, including p-cresol (Barnett et al 1994), Thaumatin (Sadik et al 1994) and polychlorinated biphenyls (Bender and Sadik 1994). Since this work there has been a huge increase in the development of electrochemical immunosensors as detailed in several recent reviews (Rodriguez-Mozaz et al 2006, Diaz-Gonzalez et al 2005, Cosnier 2005).

Antibody-antigen interactions are by their very nature complex and the reproducible response characteristics of immunosensors requires that the affinity reaction occurring is minimally perturbed by the fabrication procedure. We have previously shown that up to 2-3 Pg antibodies for BSA and digoxin may be successfully incorporated into conducting polymer films by entrapment in a growing polypyrrole film with no detrimental effect to antibody activity (Grant et al 2003). Electrochemical interrogation of these films demonstrated selective interactions with the target antigens. Further work utilised an AC impedance protocol (Grant et al 2005) as the method of interrogation for these films and led to the development of immunosensors for digoxin and bovine serum albumin.

The quinolones are a family of broad-spectrum antibiotics with the majority of quinolones in clinical use being fluoroquinolones, which have a fluoro group attached to the central ring system. They are widely used within adult patients because of excellent tissue penetration which makes them extremely effective against bacteria that grow intracellularly such as salmonella (Gendrei et al 2003). One of this group is ciprofloxacin (Figure 1) which is a broad-spectrum antibiotic active against many bacteria including anthrax (Torriero et al 2006). Many of these fluoroquinolones are added to farm animal feed since they can lead to greater and more rapid weight gain.

Unfortunately the effect of this is thought to have enabled the rise of resistant species of bacteria (Gendrei et al 2003).

The monitoring of fluoroquinolones within both food and the environment is 
important since these antibiotics have potential health and environmental damaging effects. Ciprofloxacin concentrations in hospital wastewaters were monitored and correlations with DNA damaging effects made (Hartmann et al 1999). Levels of ciprofloxacin in hospital outflow water between $0.7-124.5 \mathrm{ng} \mathrm{ml}^{-1}$ were measured using HPLC (Hartmann et al 1999) and shown to display genotoxicity at levels as low as 5.2 ng $\mathrm{ml}^{-1}$. Similar work (Batt et al 2006) measured wastewater ciprofloxacin using LC/MS/MS and found levels between 0.031-5.6 $\mathrm{ng} \mathrm{ml}^{-1}$ (even after treatment) with a limit of detection of $0.030 \mathrm{ng} \mathrm{ml}^{-1}$. Levels in vivo have also been widely studied with the therapeutic ranges typically being between $0.57-2.30 \mathrm{Pg} \mathrm{ml}^{-1}$ in serum and 1.26-4.03 Pg g-1 $_{-1}$ in tissue (Licitra et al 1987).

A recent publication (Torriero et al 2006) details the use of a horseradish peroxidase based biosensor for the detection of ciprofloxacin due to its inhibition of the oxidation of catechol, however other piperazine based compounds could potentially interfere with this determination. Linear responses were obtained between 0.02-65 PM with the limit of detection being $0.4 \mathrm{nM}$. We have within this work developed a labeless immunosensor for ciprofloxacin as a typical fluoroquinolone. The sensor utilises screenprinted carbon electrodes, modified by deposition of first, a conducting polymer (polyaniline) which is then modified with biotinylating reagent. Complexion of the immobilised biotin with avidin allows the further binding of biotinylated antibodies via standard avidin-biotin interactions (Figure 2). The resultant electrodes are capable of detecting low levels of the antigen - ciprofloxacin. Control

electrodes containing non-specific IgG have also been fabricated and allow the subtraction out of unspecific interactions.

\section{EXPERIMENTAL}

Sodium dihydrogen orthophosphate, disodium hydrogen orthophosphate, 
sodium chloride, hydrochloric acid, were obtained from BDH (Poole, Dorset, UK). Potassium chloride was obtained from Fisher Scientific UK Ltd, Loughborough, UK. Aniline, polyclonal IgG from human serum, the biotinylation kit (part no. BK101), biotin 3 -sulfo-N-hydroxysuccinimide, avidin, bovine serum albumin (BSA), potassium ferrocyanide and potassium ferricyanide were obtained from Sigma-Aldrich, Gillingham, Dorset, UK. All water used was obtained from a Purelab UHQ Deioniser (Elga, High Wycombe, UK). Commercial screen-printed carbon electrodes (Figure 3) containing carbon working and counter electrodes and an $\mathrm{Ag} / \mathrm{AgCl}$ reference electrode were obtained from Parlex Corp Ltd, Isle of Wight, UK. The surface area of the working electrode was $0.2178 \mathrm{~cm}^{2}$.

Phosphate Buffered Saline (PBS) at $\mathrm{pH} 7.4$ stock solution was prepared containing $0.14 \mathrm{~mol} \mathrm{l}_{-1} \mathrm{NaH}_{2} \mathrm{PO}_{4}, 0.52 \mathrm{~mol} \mathrm{l}_{-1} \mathrm{Na}_{2} \mathrm{HPO}_{4}$ and $0.0051 \mathrm{~mol} \mathrm{l} \mathrm{l}_{-1} \mathrm{NaCl}$. Aniline buffer ( $\mathrm{pH} 1-2)$ was prepared containing $0.5 \mathrm{~mol} \mathrm{l}_{-1} \mathrm{KCl}, 0.3 \mathrm{~mol} \mathrm{l}_{-1} \mathrm{HCl}$ and $0.2 \mathrm{~mol} \mathrm{l}_{-1}$ aniline.

Polyclonal antiserum (As 171) was raised against 1-(3mercaptopropyl)-6-fluoro7-(piperanicyl)- 1 ,4-dihydro-4-oxo-quinoline-3 -carboxylic acid coupled to $\mathrm{HCH}$. The preparation of the immunogen and of the antibodies will be described elsewhere (Pinacho et al., 2007).

For antibody biotinylation the procedure outlined in the BK101 kit was followed (see manufacturers instructions for details). Biotinylated antibodies were kept frozen in aliquots of $200 \mathrm{Pl}$ at a concentration of $1 \mathrm{mg} \mathrm{ml}^{-1}$ until required.

Cyclic voltammetry (Sycopel Potentiometer, Sycopel Scientific, Tyne \& Wear, UK) was utilised to deposit polyaniline films on the carbon electrodes. Screen-printed carbon electrodes were placed in aniline buffer and cycled from $-200 \mathrm{mV}$ to $+800 \mathrm{mV}$ vs. $\mathrm{Ag} / \mathrm{AgCl}$ for approximately 20 cycles (occasionally this was varied slightly to ensure the same amount of polyaniline was deposited on each electrode. Deposition was 
terminated at $+800 \mathrm{mV}$ to ensure the polyaniline remained in its conducting form. After deposition electrodes were rinsed in water.

$30 \mu \mathrm{l}$ of biotin-sulfo-NHS (10 $\mathrm{mg} \mathrm{ml}^{-1}$ in water) was placed on the polymer coated working electrode surface for 24 hours. The sensors were rinsed with copious water and $30 \mu \mathrm{l}$ of avidin $\left(10 \mu \mathrm{g} \mathrm{ml}^{-1}\right.$ in water) placed on the working electrode for 1 hour followed by rinsing in water. Then $30 \mu \mathrm{l}$ biotinylated antibody $\left(1 \mathrm{mg} \mathrm{ml}^{-1}\right.$ in water) was added followed by rinsing. Finally, non-specific interactions were blocked by BSA $\left(10^{-6} \mathrm{M}\right.$ in PBS); the sensors are ready to use at this point, however, if opted, can be stored in PBS at 4。C for no longer than 24 hours.

AC impedance measurements were performed using an ACM Auto AC DSP frequency response analyser. Antigen solutions for AC impedance were prepared by diluting the required concentration of antigen in $30 \mathrm{ml}$ of $\mathrm{PBS} \mathrm{pH} 7.4$. A range of concentrations were utilised, since genotoxicity is noted at levels above $5.2 \mathrm{ng} \mathrm{ml}^{-1}$; we set our minimum level at $1 \mathrm{ng} \mathrm{ml}^{-1}$ with an upper limit of $10 \mathrm{Pg} \mathrm{ml}^{-1}$, which covers the therapeutic/clinical range. However other work within our group suggests detection limits of about $10 \mathrm{pg} \mathrm{ml}^{-1}$. The sensors were first interrogated without antigen addition. Following this, each sensor was exposed to the required antigen 
concentration for 30 minutes, rinsed well with deionised water and then subjected to impedance interrogation. Potassium ferrocyanide $(10 \mathrm{mM})$ and potassium ferricyanide $(10 \mathrm{mM})$ in PBS buffer were utilised as a redox couple for impedimetric measurements. Three electrodes were used for each measurement. A frequency range from $10 \mathrm{kHz}$ to 1 $\mathrm{Hz}$ was measured, with a peak amplitude of $5 \mathrm{mV}$ and a $\mathrm{DC}$ offset of $+400 \mathrm{mV}$ against $\mathrm{Ag} / \mathrm{AgCl}$.

\section{RESULTS AND DISCUSSION}

Deposition of polyaniline

The voltammograms for the deposition of polyaniline/DNA are depicted in Fig. 4 and imply a steady in situ formation of polymer at the electrode surface. As the number of scans increases peaks appear between $+350-400 \mathrm{mV}$ vs $\mathrm{Ag} / \mathrm{AgCl}$ corresponding to the oxidation and reduction of surface bound polyaniline. The increase in current from scan 10 to 20 is due to the increase in polyaniline thickness and coverage of the electrode.

Impedance profiles of the electrodes

A series of Nyquist curves were obtained for the sensors after exposure to various levels of ciprofloxacin in PBS (Figure 5a). As can be seen, there is a steady decrease in the impedance of the electrodes with increasing antigen concentration. The relative conductivities of the system, which are obtained by dividing the impedance for each frequency with no antigen present - by the impedance (at the same frequency) for each antigen concentration are shown in Figure 5b. As can be seen, we see much larger increases in conductivity at the lower frequencies. Therefore 
it was decided that changes in impedance at $1 \mathrm{~Hz}$ would be used as a measurement of antigen binding.

The impedance spectra consists of two components, the real ( $\left.Z^{\prime}\right)$ component where the impedance in phase with the AC potential waveform is measured and the imaginary $\left(Z^{\prime \prime}\right)$ where the impedance is $180^{\circ}$ out of phase. It is important to differentiate between the individual components of the total impedance of the cell so that the capacitive and Faradaic components of the composite impedimetric response may be identified and quantified. Previous work by our group showed that while both the imaginary and real components increase, the increase in the real component dominated the total increase in the impedance (Grant et al 2005). Although in this case changes in both real and imaginary components are visible and again the real component is the major component of total impedance, perhaps more importantly it was also found that the real component offers far greater reproducibility in comparison to the imaginary contribution.

Figure $6 \mathrm{a}$ shows the percentage decrease in $\mathrm{Z}^{\prime}$ across a range of antigen concentrations. As can be seen, there is a steady decrease in impedance as antigen concentration increases up to a concentration of about $100 \mathrm{ng} \mathrm{ml}^{-1}$, above which concentration there is a tend towards a plateau, possibly indicating saturation of the specific binding sites. It is possible that any further changes in impedance beyond this level could simply be due to non-specific interactions. Between a concentration range of $1-100 \mathrm{ng} \mathrm{ml}^{-1}$, there is a near linear correlation of the impedance change with the $\log _{10}$ of concentration $\left(\mathrm{R}^{2}=0.96\right)$.

Non-specific interactions could potentially interfere with immunosensor performance. 
antibodies - or alternatively a non-specific antibody. Therefore an identical set of immunosensors were fabricated utilising a non-specific $\operatorname{IgG}$ antibody in place of the specific ciprofloxacin antibody. Results for these electrodes were obtained in exactly the same way and the calibration plot is shown (Figure 6b). As can be seen, there is a much lower response for the non-specific antibody, showing that although there are non-specific interactions, between the ranges of $1-100 \mathrm{ng} \mathrm{ml}^{-1}$, they comprise a minor component of the detected response. Figure $6 \mathrm{c}$ shows the subtracted responses $(6 a-6 b)$ and again this demonstrates linearity between the response and the $\log 10$ of ciprofloxacin concentration between 1-100 $\mathrm{ng} \mathrm{ml}^{-1}\left(\mathrm{R}^{2}=0.96\right)$.

\section{CONCLUSIONS}

We have demonstrated the construction of an immunosensor for the antibiotic ciprofloxacin using a combination of screen-printed electrodes coated with conducting polyaniline and an immobilised polyclonal antibody. Interrogation of the electrodes by AC impedance demonstrated the detection of the antigen. Linear correlation of the impedance change with the $\log 10$ of concentration $\left(\mathrm{R}^{2}=0.96\right)$ was observed between concentrations of 1-100 $\mathrm{ng} \mathrm{ml}^{-1}$.

\section{ACKNOWLEDGEMENTS}

This work has been supported by the Ministry of Science and Technology (Spain) (Contract numbers AGL2005-07700-C06-01 and NAN2004-09195-C04-04) and by the European Community Framework VI NMP2-CT-2003-505485, "ELISHA" contract. The AMR group is a consolidated Grup de Recerca de la Generalitat de Catalunya and has support from the Departament d'Universitats, Recerca i Societat de

This could be addressed by utilisation of a second sensor containing either no 
la Informació la Generalitat de Catalunya (expedient 2005 SGR 00207). DG has a FPI fellowship from the Spanish Ministry of Education. 


\section{REFERENCES}

Barnett, D. Laing, D. G. Skopec, S. Sadik, O. A. Wallace, G. G. (1994) Determination of p-cresol (and other phenolics) using a conducting polymer-based electroimmunological sensing system, Anal. Lett. 27: 24 17-2429.

Batt, A. L., Bruce, I. B., Aga, D. S., 2006 Evaluating the vulnerability of surface waters to antibiotic contamination from varying wastewater treatment plant discharges, Environ. Poll., 142: 295-302.

Bender, S. Sadik, O. A. (1998) Direct electrochemical immunosensor for polychlorinated biphenyls, Environ. Sci. Tech., 32: 788-797.

Clark, L.C and Lyons, I.R. (1962) Electrode systems for continuous monitoring in cardiovascular surgery. Ann New YorkAcademy Sci. 102: 29.

Cosnier, S., 2005, Affinity biosensors based on electropolymerized films, Electroanalysis, 17: 1701-1715.

Diaz-Gonzalez, M., Gonzalez-Garcia, M. B., Costa-Garcia, A. 2005, Recent advances in electrochemical enzyme immunoas says, Electroanalysis, 17: 1901-1918.

Grant, S., Davis, F.,. Pritchard, J. A., Law, K. A.,. Higson S. P. J.,. Gibson, T. D. 2003, Labeless And Reversible Immunosensor Assay Based Upon An Electrochemical Current-Transient Protocol, Anal. Chim. Acta., 495: 2 1-32.

Grant, S., Davis, F.,. Law, K. A.,. Barton, A. C., Collyer, S. D., Higson S. P. J.,. 
Gibson, T. D. 2005, A Reagentless Immunosensor for the Detection of BSA at Platinum Electrodes by an AC Impedance Protocol, Anal. Chim. Acta., 537: 163-168.

Gendrei, D., Chalumeau, M., Moulin, F., Raymond, J., 2003, Fluoroquinolones in paediatrics: a risk for the patient or for the community, LancetInf. Dis., 3: 537-546.

Hartmann, A. Golet, E. M. Gartiser, S. Alder, A. C. Koller, T. Widmer, R. M. 1999, Primary DNA Damage but not Mutagenicity Correlates with Ciprofloxacin Concentrations in German Hospital Wastewaters, Ach. Environ. Contam. Toxicol., 115119.

John, R. Spencer, M. Wallace, G. G. Smyth, M. R. (1991) Development of a polypyrrole-based human serum albumin sensor, Anal. Chim. Acta. 249: 381-385.

Licitra, C. M., Brooks, R. G., Sieger, B. E. (1987), Clinical Efficacy and Levels of Ciprofloxacin in Tissue in Patients with Soft Tissue Infection, Antimicrobial Agents And Chemotherapy, 31: 805-807.

Pinacho, D. G., Sanchez-Baeza, F., Marco, M. P., (2007) Development of a Class Selective Indirect Competitive Enzyme-Linked Immunosorbent Assay (ELISA) for Detection of Fluoroquinolone Antibiotics, in preparation.

Rodriguez-Mozaz, S., de Alda, M. J. L., Barcelo, D. 2006, Biosensors as useful tools for environmental analysis and monitoring, Anal. Bioanal. Chem., 386: 1025-1041.

Sadik, O. A. John, M. J. Wallace, G. G. Barnett, D. Clarke, C. Laing, D. G. (1994) Pulsed amperometric detection of thaumatin using antibody-containing poly(pyrrole) 
electrodes, Analyst. 119: 1997-2000.

Torriero, A. A. J., Ruiz-Dıaz J. J. J., Salinas, E., Marchevsky, E. J., Sanz, M. I., Raba,

J., 2006, Enzymatic rotating biosensor for ciprofloxacin determination, Talanta, 69: 691-699.

Yalow, R. S. Berson, S. A (1959) Assay of Plasma Insulin in Human Subjects by Immunological Methods, Nature. 184: 1648-1649. 


\section{LIST OF FIGURES.}

Figure 1. Structure of ciprofloxacin.

Figure 2. Schematic of antibody modified electrodes.

Figure 3. Screen-printed carbon electrodes used within this work.

Figure 4. Deposition of conducting polyaniline films by cyclic voltammetry, curves shown after 1,10 and 20 cycles.

Figure 5. Nyquist plots of a typical antibody modified electrode exposed to various concentrations of antigen.

Figure 6. Calibration curves for (a) anti-ciprofloxacin modified electrodes (b) IgG modified electrodes (c) corrected calibration curves (curve a - curve b). All data points are averages of three electrodes; error bars give a measure of the reproducibility of the system. 

Fig 1<smiles>O=C(O)c1cn(C2CC2)c2cc(N3CCNCC3)c(F)cc2c1=O</smiles> 
Fig 2

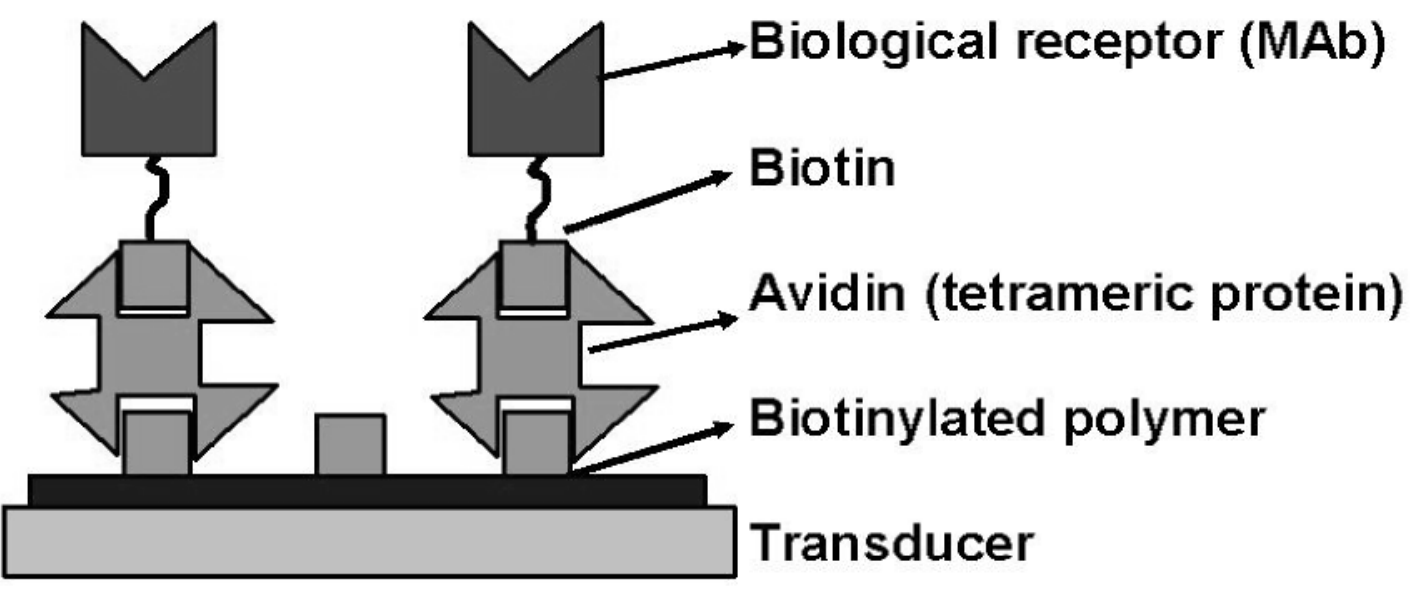


Fig 3

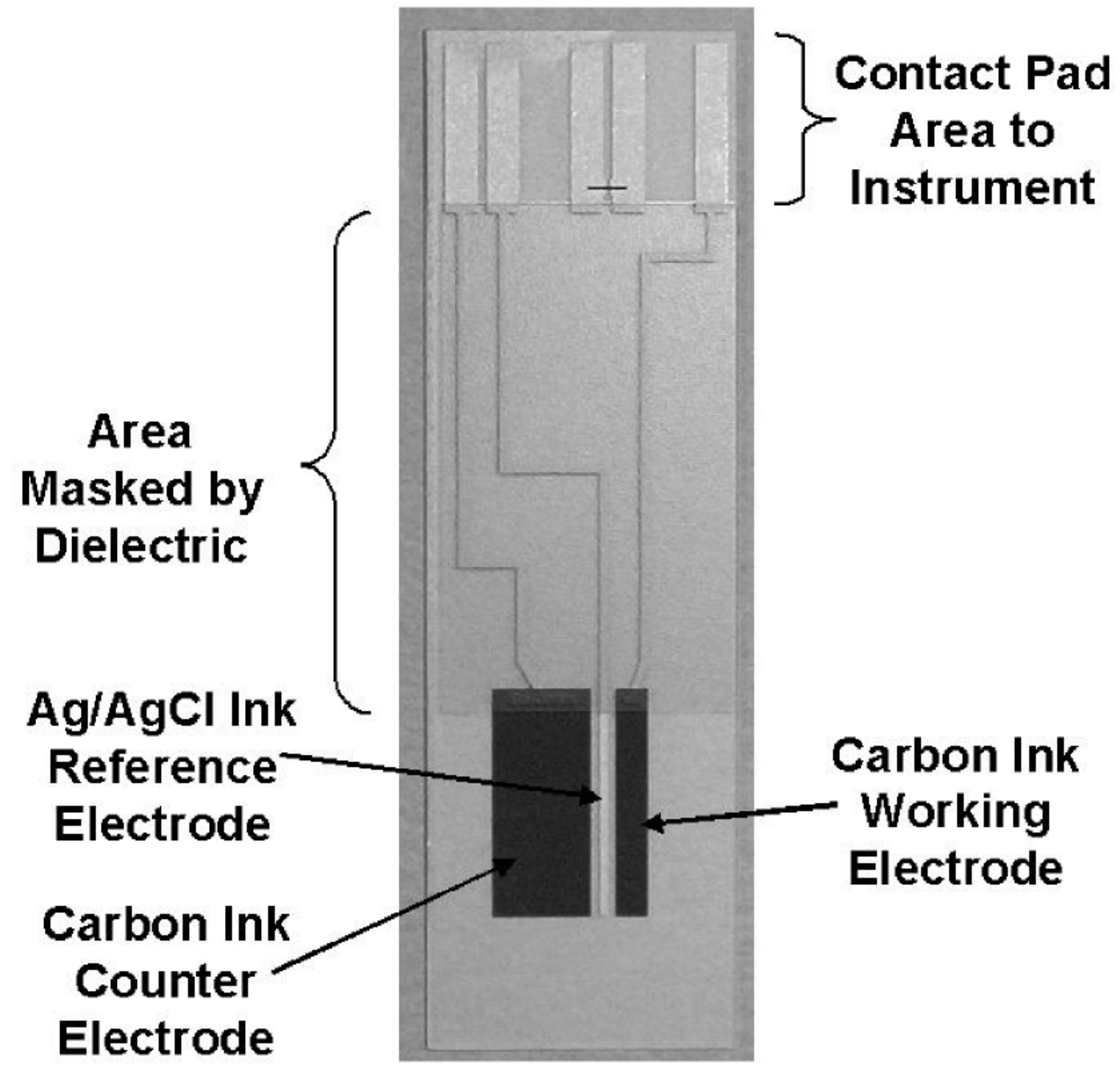


Fig 4

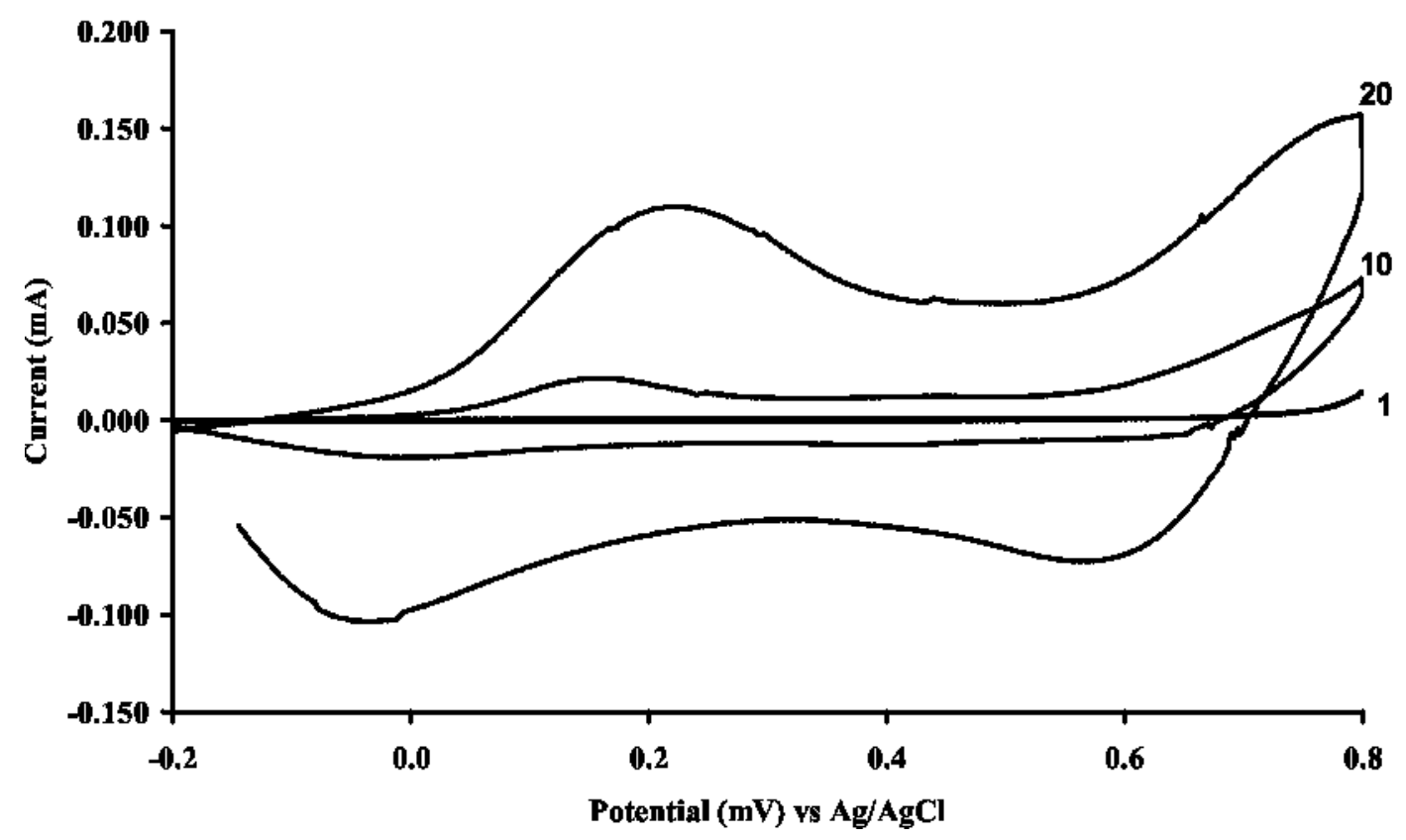


Fig 5
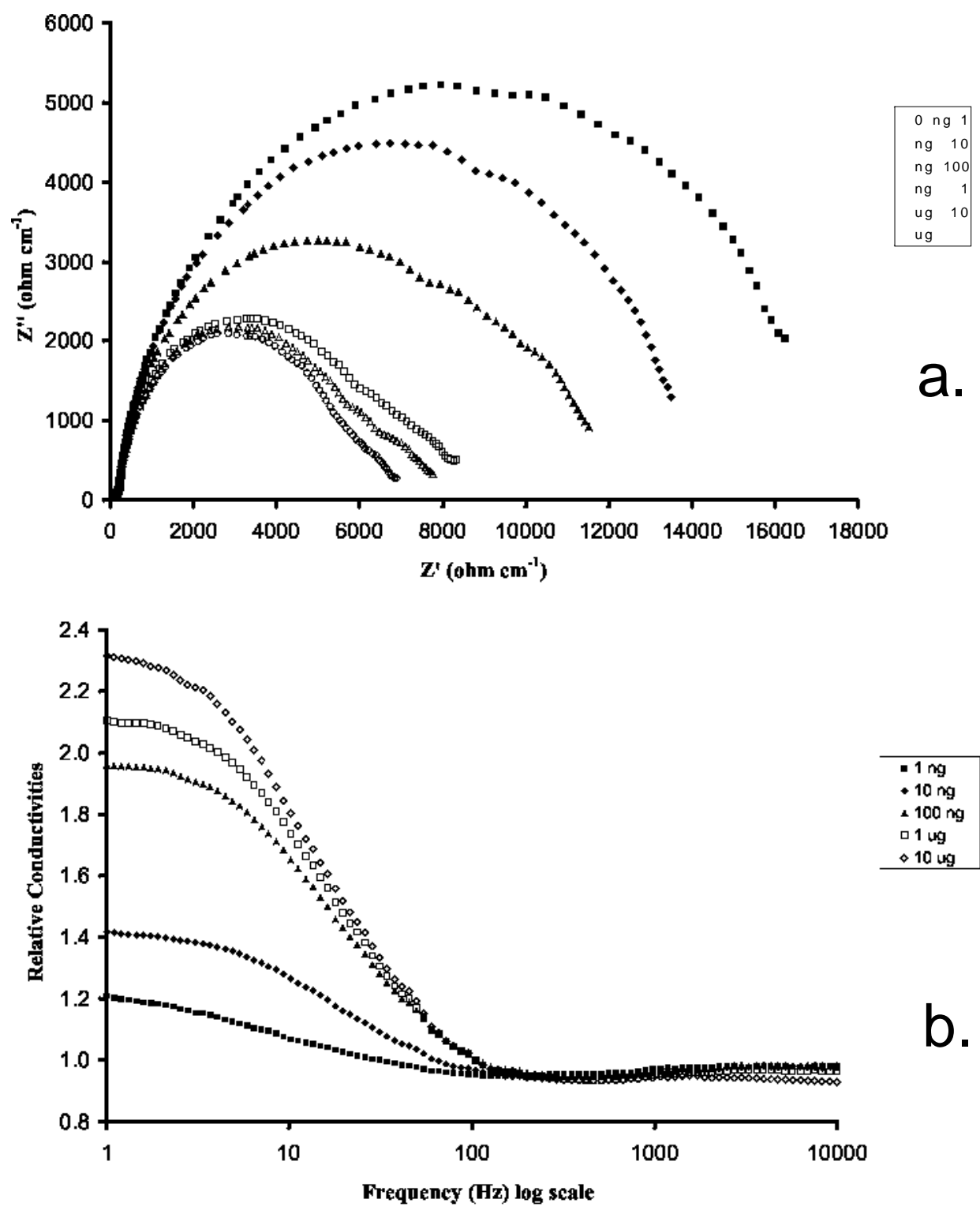
Fig 6

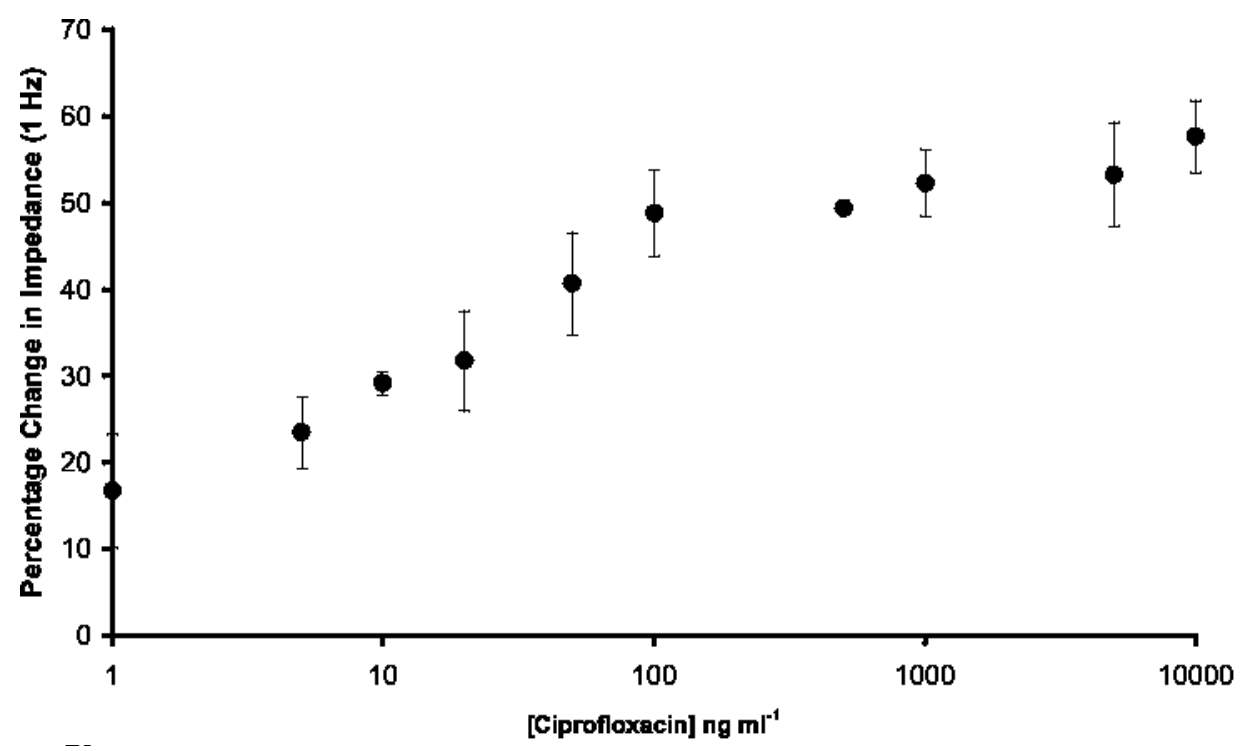

a.
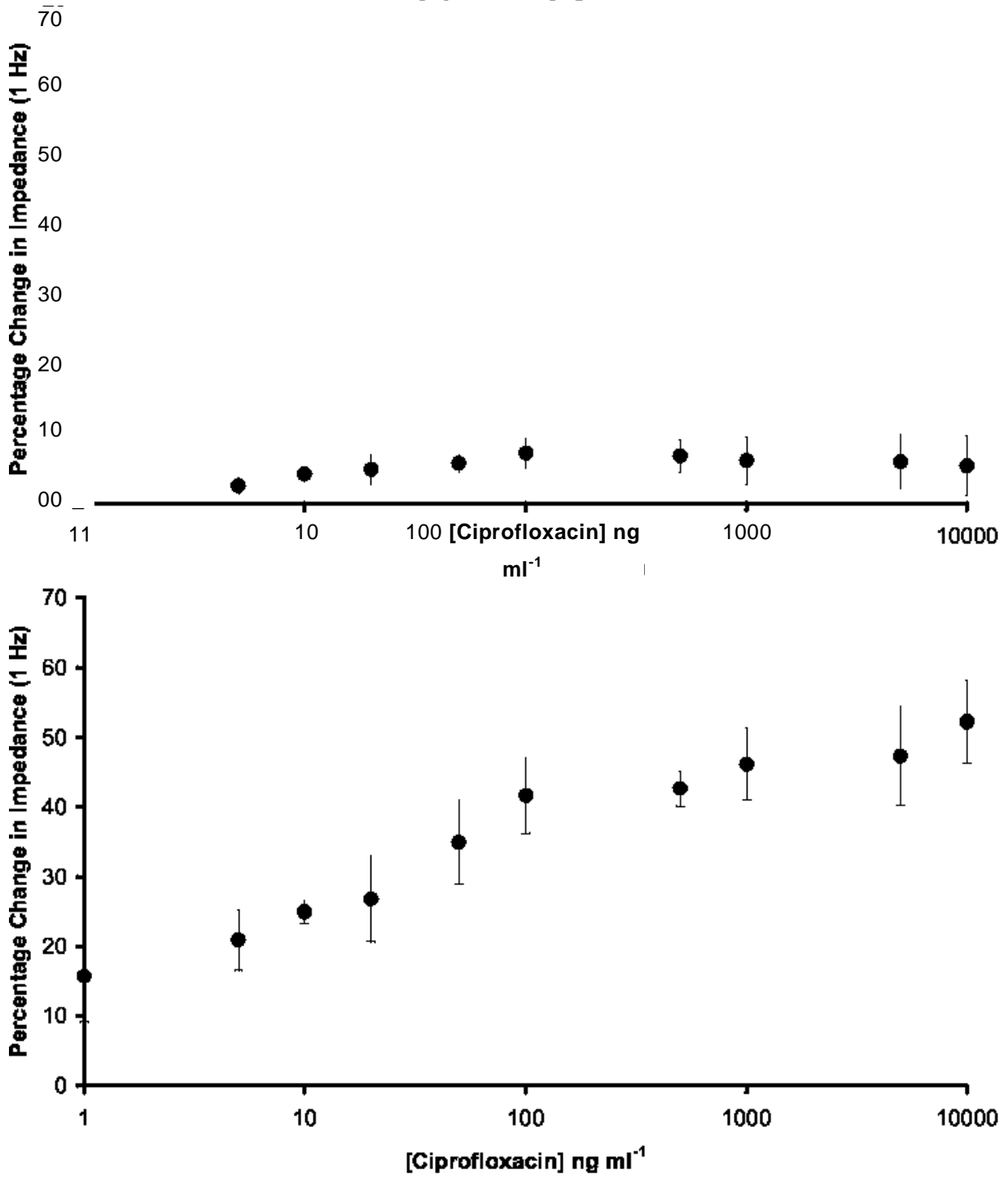